\title{
First Do No Harm: Emotional Maltreatment in the Classroom
}

\author{
Margaret A. King · Gregory R. Janson
}

Published online: 27 June 2009

(C) Springer Science+Business Media, LLC 2009

\begin{abstract}
Emotional maltreatment of children is occurring in classrooms daily and professionals sometimes are unaware of it. We are bound by a Code of Ethics, which states that we have a responsibility to intervene when children are harmed. Most professionals are unaware of how emotional maltreatment looks in the classroom and what they can do to prevent it. We have addressed what emotional maltreatment look like in the classroom and what teachers and parents can do to help to change this frequently occurring situation. The editorial presents a scenario of a first grade child who is experiencing emotional maltreatment in the classroom and strategies for parents and professionals to use when they observe emotional maltreatment in the classroom.
\end{abstract}

Keywords Emotional maltreatment - Ethical Conduct . Code of Ethics - Teachers · Young children

All of us have beliefs about what should and should not happen to children while they are in educational institutions such as schools and early childhood programs. For those of us who work with young children, those beliefs are embedded in a Code of Ethics, specifically the NAEYC

M. A. King ( $\square)$

Early Childhood Education, School of Human and Consumer Sciences, W324 Grover Center, College of Health and Human Services, Ohio University, Athens, OH 45701, USA

e-mail: kingm@ohio.edu

G. R. Janson

Family Studies, School of Human and Consumer Sciences, W324 Grover Center, College of Health and Human Services, Ohio University, Athens, OH 45701, USA
Code of Ethical Conduct (NAEYC 2005). In the NAEYC Code of Ethical Conduct, P-1 states: "Above all, we shall not harm children. We shall not participate in practices that are emotionally damaging, physically harmful, disrespectful, degrading, dangerous, exploitative, or intimidating to children" (NAEYC 2005, 3). This principle provides the foundation for all ethical decision-making and ranks first among ethical principles: do no harm. Even though most early childhood educators would say that we believe in this principle and it provides the foundation for classroom, program, and school practices, we often observe children in harmful situations and do not act. Our inaction occurs because we may not recognize the situation as harmful or we may deny that it is possible for the situation to occur in schools. We will describe a harmful situation that occurs frequently in classrooms and schools and suggest ways that professionals can be responsive to the NAEYC Code of Ethical Conduct as they advocate for children.

Robert is in the first grade. Each morning when Robert enters the classroom, the teacher, Ms. Jones greets him with a smile. Ms. Jones is an experienced teacher. She is a friendly woman who has very specific ways for children to behave in her classroom. When children enter, they know that they are to put their jackets and backpacks away and go to group meeting. Robert is always late getting to group meeting and Ms. Jones responds in the same way each day. She says, "Robert, I am glad that you finally decided to join us. You are such a slowpoke. If you are going to do well in my classroom, you need to get to group meetings on time. We have to wait for you every day and we are tired of your tardiness. Aren't we class?" Everyone yells, "Yes!" Then Ms. Jones asks if any of the students have anything to say to Robert about making the class late starting meeting. Several students respond to her request with negative comments. Ms. Jones continues by saying to Robert, "If 
you continue to be late, the class will have to give up recess to make up the time." Then group meeting begins.

Throughout the day, Robert has similar encounters with Ms. Jones, who prides herself on her patience, even-temperedness, and that she never yells at children. However, Robert's day is filled with missed recess, scolding for not listening or talking to his neighbor, and reprimands for asking to go to the bathroom when it is not the appropriate time. He is often ridiculed for creating a messy workspace. Sometimes, in frustration, Ms. Jones takes everything out of Robert's desk and cleans it out while the other children are watching. When all else fails, Ms. Jones reminds Robert that he is in first grade now and no longer in kindergarten but if he continues to be a baby, she will have him moved back to kindergarten. Throughout the day, Robert hears the phrase "You are no longer in kindergarten and in first grade we behave this way. If you can't act like a first grader, I will have you moved back to kindergarten."

Although many educators are in denial that teachers such as Ms. Jones exist, they surely do. As educators, we cannot believe that the types of behavior exhibited by Ms. Jones could occur in a classroom or school without intervention. We, the authors, know that this type of behavior occurs because we often meet parents who know Robert because he is their child. We meet teachers who know Robert because he is in a colleague's classroom. We have talked with many children and adults about their schooling experiences and they retell the story of Robert because they were Robert. The culture that Ms. Jones created for Robert in the classroom is not unlike the culture that many children encounter each day while in school. While it is true that no one has struck Robert, or even yelled at him, he has been subjected to a steady stream of shaming, ridiculing, and labeling that diminishes his self-concept, erodes his sense of competence, and negatively impacts the way his peers view him. This type of emotional maltreatment is often unrecognized and unacknowledged and is accepted as standard practice in many schools. As a result, administrators, teachers, and others who are responsible for creating a safe and secure learning environment often inadvertently use practices that are not in the best interests of children and have the potential to cause significant harm to them.

\section{A Call to Action}

As professionals, we need to respond to emotional maltreatment when we see it in schools and early childhood programs. We need to recognize the harm, label the harm, and act.
Recognize the Harm

We must first recognize that the teaching practices used by Ms. Jones are causing harm. The harm is often difficult to recognize because it is perpetuated by professionals and woven into the fabric of classroom management strategies. Teachers may not see shaming, teasing, ridiculing, humiliating, and labeling children as maltreatment, but it is maltreatment, especially when it defines a pattern of interaction over time. In classrooms, the use of these behaviors are often rationalized as disciplinary actions that are a necessary means to maintain order and gain children's compliance in the classroom.

Children who observe these interactions between the teacher and the child typically believe that the punishment is justified and they may also blame the child, the victim, for not behaving appropriately. They may even say, "If Robert would behave appropriately, Ms. Jones would treat him better". Some children may even taunt Robert or agree with Ms. Jones as when Ms. Jones asked if all of the children were tired of waiting for Robert and they all yelled "yes". When children see other children being emotionally maltreated, they often feel anxiety, fear and relief-relief that they are not the target of adult displeasure and fear that they may become the next target of the teacher's displeasure. Ms. Jones is harming Robert and she is modeling behaviors that other children can use to harm Robert and others in the class who do not meet Ms. Jones' definition of a good student.

\section{Label the Harm}

It is important for us as educators to label the harm and use terms such as emotional maltreatment or emotional abuse to describe these types of interactions between children and teachers. Since emotional maltreatment is often not transparent it is important to identify and label the behaviors that Ms. Jones exhibits that cause harm to Robert. Researchers have defined emotional maltreatment as a systematic pattern of negative interactions that occur between a child and an adult over time (Garbarino and Vondra 1987; Briggs and Hawkins 1997; Kairys et al. 2002). The behaviors associated with emotional maltreatment are spurning, defined as belittling, shaming, ridiculing, singling out, and humiliating a child (Kairys et al. 2002); terrorizing, creating an emotionally unsafe environment for a child (Garbarino and Vondra 1987; Briggs and Hawkins 1997; Kairys et al. 2002); isolating, limiting contact with others (Garbarino and Vondra 1987; Briggs and Hawkins 1997; Kairys et al. 2002); rejecting, lack of acknowledge of the child's needs or work or viewing the child as a failure (Garbarino and Vondra 1987; Briggs and Hawkins 1997; Kairys et al. 2002); denying emotional 
responsiveness, lack of affection, caring, and understanding of the child (Garbarino and Vondra 1987; Briggs and Hawkins 1997; Kairys et al. 2002); over pressuring, pushing a child to grow up too fast or having expectations beyond the child's age and developmental level; and exploiting or corrupting, encouraging the child to develop inappropriate behavior (Garbarino and Vondra 1987; Briggs and Hawkins 1997; Kairys et al. 2002).

\section{Identify the Harm to Robert}

Ms. Jones uses many of the techniques identified above as emotional maltreatment to manage Robert's behavior and force his compliance. When Robert came to the group, Ms. Jones would ask the other children if they were tired of his tardiness, encouraging them to yell out "yes"- and there could only be one correct answer. Then she asked individual children to comment about Robert's tardiness. By enlisting the support of other children in the classroom, Ms. Jones corrupted and exploited them by encouraging them to participate in the emotional maltreatment of Robert. This was not part of a democratic process because the children knew that they needed to make a negative comment-there could only be one response. Robert became the scapegoat of the classroom and was rejected by his teacher and peers, leaving him isolated and denying him any source of validation or support.

Ms. Jones also used the technique of spurning to interact with Robert. Ms. Jones frequently singled out Robert for not getting to circle time on time, for having a messy desk, and for not meeting the expectations of first grade. Robert was constantly shamed and humiliated by Ms. Jones and when that did not work, Ms. Jones would further isolate Robert from his peers by not allowing him to participate in recess-or worse, denying recess to the entire class and blaming Robert.

Ms. Jones may not be aware of Robert's developmental abilities and not realize that her expectations may well exceed Robert's capabilities. By pressuring Robert to perform beyond his abilities, Ms. Jones has created an environment where Robert feels that he is unable to meet expectations and will come to see himself as a failure. Whatever her motives or intentions, Ms. Jones failed to provide Robert with a caring, safe and emotionally responsive environment. Day to day, Robert lived in fear of not meeting Ms. Jones' expectations and receiving the ultimate humiliating consequence of having to return to kindergarten.

\section{Act}

As colleagues of Ms. Jones or other professionals who engage in similar behaviors we must take action and respond to their behavior. We are most likely to become aware of the behavior before the perpetrator becomes aware of its detrimental effects. The negative pattern of interactions may reflect Ms. Jones' frustrations with Robert, a tacit power struggle between them, or a misunderstanding of Robert and his capabilities. Whatever the reasons, the negative impact on Robert creates an ethical responsibility for us as colleagues to intervene on Robert's behalf as soon as we become aware of the situation. According to NAEYC Code of Ethical Conduct (2005), we should protect children when we become aware of any practice that endangers the well-being of any child (Principle-1.11). The principle does not distinguish between types of harm (physical or emotional), and does not exempt "accepted practice" from the obligation to intervene. Given the clearly demonstrated potential for harm created by emotional maltreatment and its multiple threats to children's well-being, we have no choice but to intervene. We should find a way to communicate with the perpetuator in a way that shows concern and respect and that is based on firsthand knowledge rather than hearsay (Principle-3A.2; Principle-3A.3).

First and foremost we must put the best interest of children first by supporting best practice. Instead of supporting or remaining silent when a colleague speaks negatively about a child in the teacher's lounge or hallway, colleagues should tactfully describe experiences that they have had with similar children and how they handled the situation in a more appropriate, affirming manner. Even a small comment has the potential to help refocus a teacher who is using these practices. Colleagues should also model positive interpersonal communication strategies and share resources that describe more appropriate classroom management strategies and discuss those practices with the colleague.

Second, we must make emotional maltreatment visible in the school or program. Talk about emotional maltreatment with teachers, administrators, and children. Encourage the principal to devote some of the school's professional development to creating emotionally safe classrooms for children through discussions and trainings. Inform others including parents and support staff so that they can also recognize and respond to emotional maltreatment. Inform supervisors and administrators that you have observed emotional maltreatment in the school. Let them know what you have observed and encourage them to act.

Finally, think about your current situation. Have you observed emotionally maltreatment of children? When and where did you observe it? What did you do about it?

\section{Conclusion}

Changes to the school climate is often a long process but we have an obligation to follow a code of ethical behavior 
and to establish classroom practices that are in the best interest of the children we teach. The NAEYC Code of Ethics is a critical resource in helping professionals determine whether their personal notions of what is best practice truly promotes what is best for children. Confronting colleagues who may be engaging in the emotional maltreatment of their students is never easy, but the ethical obligation to intervene when children are harmed must remain the primary consideration: first do no harm. Emotional maltreatment has no place in environments that serve children.

\section{References}

Briggs, F., \& Hawkins, R. (1997). Child protection: A guide for teachers and early childhood professionals. Crows Nest, Australia: Allen and Unwin.

Garbarino, J., \& Vondra, J. (1987). Psychological maltreatment: Issues and perspectives. In M. R. Brassard, R. Germain, \& S. N. Hart (Eds.), Psychological maltreatment of children and youth. New York, NY: Pergamon Press.
Kairys, S., Johnson, C., \& The Committee on Child Abuse and Neglect. (2002). The psychological maltreatment of childrentechnical report. Pediatrics, 109(4), 1-3.

National Association for the Education of Young Children. (2005). NAEYC code of ethical conduct and statement of commitment. Washington, D.C.: NAEYC.

\section{Additional Readings}

Brendgen, M., Wanner, B., Vitaro, F., Bukowski, W., \& Tremblay, R. (2007). Verbal abuse by the teacher during childhood and academic, behavioral, and emotional adjustment in young adulthood. Journal of Educational Psychology, 99(1), 26-38.

McEachern, A., Aluede, O., \& Kenny, M. (2008). Emotional abuse in the classroom: Implications and interventions for counselors. Journal of Counseling and Development, 86(1), 3-10.

McKenzie, K. (2009). Emotional abuse of students of color: The hidden inhumanity in schools. International Journal of Qualitative Studies in Education, 22(2), 129-143.

Nesbit, W. C., \& Philpott, D. F. (2002). Confronting subtle emotional abuse in classrooms. Guidance and Counseling, 17(2), 32-38.

Shumba, A. (2004). Emotional abuse in the classroom: A cultural dilemma? Journal of Emotional Abuse, 4(3/4), 139-149. 